\title{
Devir e destruição: pensando a relação indivíduo-cultura a partir de Freud e Spielrein
}

\author{
Coming Into Being and destruction: thinking about the individual-culture \\ relationship from Freud end Spielrein
}

\section{Carlos Eduardo de Moura*}

Resumo: Partindo da afirmação de Freud de que devemos pensar nos mecanismos psíquicos estruturantes de uma personalidade sondando-os dinamicamente, isto é, considerando a ação conjugada entre dimensão constitucional (destino, forças internas) e vivências contingentes (poderes externos), a oposição entre psicologia individual e psicologia social perde sua nitidez. A série complementar necessidade-contingência requer uma reflexão sobre o processo de individuação que envolve tanto as representações de um passado filogenético (verdade pré-histórica) quanto as vivências casuais de uma biografia (verdade individual). É apoiado nesse contexto que pretende-se mostrar o quanto Spielrein e Freud possibilitarão pensar sobre o modo pelo qual a morte, a destruição e o aniquilamento poderão ser compreendidos como possibilidade de transformação e devir: entre a psique do Eu (autoconservação) e a psique da espécie (diluição do Eu em um Nós) o indiferenciado (pré-história da espécie) é espacializado e temporalizado (elementos contingentes do campo interpsicológico e histórico).

Palavras-chave: Pulsão; Freud; Spielrein; Destruição; Devir; Homem aculturado

Abstract: Starting from Freud's statement that we must think about the structuring psychic mechanisms of a personality by dynamically probing them, that is, considering the combined action between the constitutional dimension (destiny, internal forces) and contingent experiences (external powers), the opposition between individual psychology and social psychology loses its sharpness. The complementary series of contingency needs requires a reflection on the process of individuation that involves both representations of a phylogenetic past (prehistoric truth) and casual experiences of a biography (individual truth). It is supported in this context that it is intended to show how much Spielrein and Freud will make it possible to think on the way in which death, destruction, annihilation can be understood as the possibility of transformation and becoming: between the psyche of the I (self-preservation) and the psyche of the species (dilution of the I into a We) the undifferentiated (prehistory of the species) is spatialised and temporalized (contingent elements of the interpsychological and historical field).

Keywords: Drive; Freud; Spielrein; Destruction; Coming Into Being; Culture

"Pós-Doutorando em Psicologia, com o Projeto de Pesquisa em Freud (FFCLRP-USP/FAPESP), Universidade de São Paulo, Ribeirão Preto, SP. E-mail: cemoura73@gmail.com ORCID: https://orcid.org/0000-0003-2318-3463 


\section{Considerações iniciais}

Uma indagação psicanalítica, visando apreender os processos psíquicos que sustentam o drama de um paciente, procurará nos dados da biografia tanto os episódios contingentes e as influências do meio quanto as informações levantadas sobre as reações desse indivíduo. Com isso, a Psicanálise nos convida a investigarmos os mecanismos psíquicos estruturantes de uma personalidade sondando a natureza do indivíduo dinamicamente [dynamisch $z u$ ergründen] e trazendo à luz suas forças anímicas originárias. Estas, por sua vez, passam por transformações e desenvolvimentos que atravessam as vivências externas ao longo do caminho da atividade pulsional: cada um de nós corresponde a essas ragioni da natureza (necessidade-contingência) que penetram na experiência ${ }^{1}$. Trata-se, portanto, de estabelecer, não uma relação de oposição de princípios da série complementar disposição e acaso, mas da ação regular conjugada entre os dois fatores que a compõe - quando um aumenta, o outro diminui.

É a partir da individuação dessa ação conjugada que se apresenta a problemática entre as representações que pertenceriam a um passado que ultrapassaria o âmbito do indivíduo (passado filogenético) e as vivências contingenciadas na defesa contra a diluição do Eu em um Nós de uma personalidade em vida. Em outros termos, disposição e acaso incluiria uma reflexão sobre as tensões que mobilizariam o aparelho anímico entre os fatores da realidade nos tempos originários da família humana (compondo a verdade préhistórica [prähistorischer Wahrheit]) e os fatores de individuação e diferenciação (de uma verdade individual [individuellen Wahrheit]) ${ }^{2}$. No caso, a relação entre o Eu e o Nós terá como ponto de partida uma das observações de Freud em Totem e Tabu (1913), a saber, a suposição

de uma psique das massas, em que os processos psíquicos ocorrem tal como na vida anímica de um indivíduo. [...] Sem a hipótese de uma psique das massas, de uma continuidade na vida de sentimentos dos seres humanos que permita superar as interrupções dos atos anímicos produzidos pela morte dos indivíduos, não poderia haver psicologia dos povos. Se os processos psíquicos não continuassem de uma geração para a seguinte, se cada uma tivesse que adquirir de novo seu posicionamento ante a vida, não haveria progresso nesse campo e quase nenhum desenvolvimento. Então surgem duas novas questões: o quanto pode ser atribuído à continuidade psíquica na sequência de gerações, e de quais meios e caminhos serve-se uma geração para transmitir à geração seguinte os seus estados psíquicos ${ }^{3}$.

\footnotetext{
${ }^{1}$ Cf. FREUD, Un recuerdo infantil de Leonardo da Vinci, pp. 125-27.

${ }^{2}$ Cf. FREUD, 23ㄹ conferencia. Los caminhos de la formación de sintoma, p. 338.

${ }^{3}$ FREUD, Tótem y Tabú, p. 159.
} 
Entre as moções ternas e hostis que compõem as vivências afetivas e governam as constelações da psicossexualidade, a psicologia individual e a psicologia dos povos ou etnopsicologia encontram seu enraizamento: a permanência "do persistente conflito entre

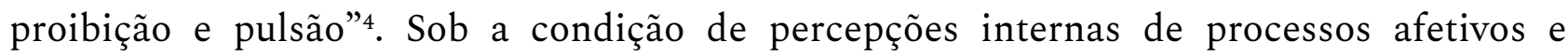
sensoriais e sob a condição dos processos de pensamento, a configuração do mundo externo traz em suas manifestações tanto processos psíquicos indestrutíveis e incorrigíveis do inconsciente, quanto criações culturais [Kulturschöpfungen] conjugadas com a religião, a moralidade, a sociedade e a arte. Freud e Spielrein, dado este contexto, permitirão estabelecer algumas reflexões sobre as forças pulsionais que colocam o conteúdo psíquico em movimento sob dois aspectos: da ambição de se autoconservar e do desejo de destruição. Entre a configuração da realidade psíquica e a realidade fática ou histórica, não só a relação inato-adquirido se insere nessa configuração, mas também as tensões mobilizadoras entre o Nós e o Eu que estruturam tais realidades.

Como veremos, essas tensões mobilizadoras, que assumem um valor organizacional do aparelho anímico, compõem-se também pela formação de conflito entre as pulsões do Eu e as pulsões sexuais diante da (im)possibilidade de satisfação, portanto, fala-se aqui das exigências das pulsões sexuais que aparecem ao Eu como ameaça à sua autoconservação e autoestima. Acrescenta-se, com isso, que as exigências de descarga e satisfação pulsionais lançam-se em um jogo de investimentos em que o empenho erótico, a capacidade de amor e o uso da libido dão-se na relação com os objetos em um contexto cultural. Duas observações se colocam como consequência desse lançar-se à: 1) as exigências das pulsões sexuais transbordam o indivíduo [Einzelwesen hinausgreifen] na medida em que aparecem como perigo, ameaça à autoconservação ou à autoestima e, 2) apoiada na satisfação das grandes necessidades vitais, a libido transborda (überfließt] do Eu para os objetos externos para novamente desfazer-se deles e retirar-se para o $\mathrm{Eu}^{5}$.

É por meio desta interação dialética de progressão (Eu $\rightarrow$ Objetos externos) e regressão (Objetos externos $\rightarrow \mathrm{Eu}$ ) da libido e da vida anímica - portanto, através de aspirações sujeitas a uma compulsão por unificar e reunir ${ }^{6}$ - que podemos ampliar o conceito de sexualidade e de pulsão sexual estendendo-os também àquilo que não se subordina à função reprodutiva ${ }^{7}$. O homem, inevitavelmente, encontrar-se-á lançado na lida com os imperativos morais e culturais que produzem a história de seu padecimento.

Apresentadas tais observações preliminares, Spielrein e Freud podem auxiliar-nos nas reflexões sobre o fracasso da idealização do projeto civilizatório e da consequente desilusão que os conflitos e as contradições que envolvem o indivíduo e a sua participação

\footnotetext{
${ }^{4}$ Idem, p. 37.

${ }^{5}$ Cf. FREUD, Una dificultad del psicoanálisis, pp. 130-131.

${ }^{6}$ Segue daí a noção do Eu enquanto psicossíntese [Psychosynthese] - FREUD, Nuevos caminhos de la terapia psicoanalitica, p. 157.

${ }^{7}$ Cf. FREUD, Más allá del principio de placer, p. 50.
} 
na comunidade humana revelam: a destruição, a guerra e o mal não foram (e um dia serão?) erradicados com a produção do homem aculturado. Este fato coloca em investigação aquilo que mobiliza a construção (enquanto criação, ligação, investimento) e a destruição (enquanto desinvestimento, aniquilamento) que atravessam a relação indivíduo-grupo, seja sob os aspectos da (a)temporalidade (herança arcaica) ou pela perspectiva da casualidade das relações objetais e intersubjetivas.

Isto posto, pretendo, neste artigo, focar na importância do pensamento da médica e psicanalista russa Sabina Spielrein para apresentar algumas de suas provocações teóricas, ainda que de forma incompleta, aos que se interessam pelo estudo da história da psicanálise. É com essa motivação que procurarei focar em seu Ensaio " $A$ destruição como origem do devir" e, a partir de algumas de suas noções metapsicológicas, percorrer certas obras de Freud que me foram provocadas pela leitura deste importante trabalho spielreiniano de 1912.

\section{Apresentação do problema: o indivíduo e a massa}

A temática da Guerra possibilita, dentre outros pontos, uma proximidade de Spielrein e Freud. Inicio, portanto, por esta escolha relembrando-nos que em Considerações atuais sobre a guerra e a morte (1915), Freud nos traz algumas reflexões sobre o tema da desilusão causada pela guerra para colocá-la à luz de uma investigação psicanalítica: Qual seria a essência pulsional dos homens? Como pensar na história da humanidade e na sua aptidão para a cultura? Como compreender a morte (enquanto hostilidade ou desejo inconsciente de morte) e sua relação com os componentes de nosso próprio Eu? Ora, também para Spielrein, "A guerra remete a representação da destruição" ", mas também é preciso pensar a destrutividade em relação com a vida, com os componentes do Eu e com o próprio instinto de procriação. Com isso, se coloca a reflexão sobre o modo pelo qual a morte, a destruição e as estruturas da cultura estabelecem um vínculo entre a psicologia individual e a psicologia das massas.

Freud, em Totem e Tabu (1913), procurou marcadamente debruçar-se sobre esse vínculo, influenciando profundamente o diálogo entre a Psicanálise e as disciplinas das Ciências Sociais ao longo do século XX (Malinowski, Géza Róheim, Tobie Nathan, LéviStrauss, dentre outros). Em Psicologia das massas e análise do eu (1921), por exemplo, ele nos mostrará que cada indivíduo participa da alma de muitas massas [vielen Massenseelen] - raça, classe, comunidade religiosa ou Estado - por uma multiplicidade de vínculos de identificação edificadas pelo ideal do eu e seus diversos modelos. Por outro lado, esse mesmo indivíduo, afirmará Freud, poderá elevar-se para além delas na qualidade de uma

${ }^{8}$ SPIELREIN, A destruição como origem do devir, p. 247. 
partícula de autonomia e originalidade [Selbständigkeit $]^{9}$. Portanto, Psicologia individual e Psicologia das massas ou social perderá a sua riqueza - como lemos logo na Introdução da obra - se a considerarmos como sendo opostas.

É nessa espécie de tensão indivíduo-grupo que a relação entre a pré-história da família humana e o surgimento de fortes investimentos afetivos - que se impõe à psique no âmbito de uma psicologia individual - lança a questão sobre os fatores de uma predisposição hereditária e constitucional e os fatores vivenciais ou acidentais das impressões da primeira infância. Disso resulta a tensão acima referida: "dois fatores se juntam para produzir uma etiologia, a medida menor de um é compensada pela medida maior de outro, em geral há uma convergência dos dois" ${ }^{10}$. A vida inconsciente, no caso, é apreendida na função de criação de uma tonalidade afetiva e mnêmica por ela estruturada e manifesta na vivência consciente sublimada, deslocada, deformada ou recalcada. Esta, por sua vez, ainda que traga um nível de (in)adaptação às exigências do mundo externo real, enraíza-se na sedimentação das vivências de uma ancestralidade.

A genealogia do aparelho psíquico [...] apresenta-nos a psicanálise como uma psicologia em que o psiquismo individual se alicerça em bases coletivas e, por sua vez, esse cunho social se enraíza numa espécie de memória histórica inscrita na própria forma do psiquismo ${ }^{11}$.

Falar nessa sedimentação consiste em compreender a profundidade de uma parcela do Eu constituído, “em parte, de 'representações' que parecem pertencer a um passado que ultrapassa o âmbito do indivíduo" 12 e, ao mesmo tempo, representações e afetos que se inserem em uma vivência presente. Uma personalidade em vida, por consequência, encontra-se alicerçada na tensão entre uma temporalidade caracterizada pela diferenciação (ou nexos de representações diferenciadas em um drama individual) e uma atemporalidade sedimentada filogeneticamente (como representações generalizadas e típicas).

Se considerarmos a Segunda Tópica, essa relação (a)temporal pode ser colocada no âmbito dos conflitos entre o Eu e o Ideal, entre o psíquico (mundo interior) e o mundo exterior. Freud avançará em suas análises e nos mostrará o quanto, nessa relação (a)temporal e espacial, as vicissitudes da espécie humana deixaram no Id uma marca ou uma sequela assumida pelo Eu através da formação desse ideal: a universalidade da espécie é revivenciada na singularidade. O Eu, instância individual, conflui com as aquisições filogenéticas do Id e das anteriores formações de outros $E u$ que, por consequência, deixaram seus precipitados no Id (na qualidade de instância filogenética).

\footnotetext{
${ }^{9}$ Cf. FREUD, Psicología de las masas y análysis del yo, p. 122.

${ }^{10}$ FREUD, Moisés e o Monoteísmo: três ensaios, p. 104.

${ }^{11}$ BAIRRÃO, Prefácio, p. 14.

${ }^{12}$ SPIELREIN, Sobre o conteúdo psicológico de um caso de esquizofrenia, p. 215.
} 
Desse modo, o Id hereditário alberga em seu interior os resíduos de inumeráveis existências-eu [Reste ungezählt vieler Ich-Existenzen] e quando o Eu extrai do Id [a força para] seu Super-Eu, quiçá apenas faça aparecer de novo figuras, formas de Eu mais antigas, proporciona-lhes uma ressurreição ${ }^{13}$.

Freud, portanto, dá-nos conta de que na vida psíquica do indivíduo agem conteúdos vivenciados na singularidade de sua existência, mas também elementos de uma herança arcaica (predisposições, conteúdos, traços mnêmicos de vivências das gerações antigas) que o conduz a determinadas direções de desenvolvimento, isto é, a reações de caráter universal a excitações, impressões e estímulos ${ }^{14}$. Assim sendo, pensar na estruturação do aparelho psíquico dar-se-á sob os aspectos da ação conjugada entre herança e aquisiçãa ${ }^{15}$. Em outros termos, a constituição (herança) ou o precipitado sobre a série infinita dos antepassados segue em ação mútua com magnitudes que se (re)arranjam em variáveis à luz da vida psíquica do indivíduo. Contextualiza-se, com isso, a temática de uma verdade individual - no sentido de um movimento de diferenciação ou de unidade válida para o Eu - e de uma verdade pré-histórica - no sentido de um movimento de assimilação, de vivência da espécie ou da conversão do Eu em Nós. É nesse movimento que pulsão de morte, destruição e devir apresentam-se aqui como um importante fio condutor para a reflexão seguinte que se apresentará entre Freud e Spielrein.

\section{O intrassomático e as relações sociais: a formação de caráter entre amor e ódio}

Freud, em 1915, publica o texto Considerações atuais sobre a guerra e a morte, em que é possível verificar uma relação entre a destruição (manifesta no âmbito da História) e a satisfação de certas necessidades originais à condição humana ou às condições constitucionais emaranhadas com o contexto sociocultural. Trata-se de pensarmos em moções pulsionais presentes e atuantes em todos os homens que, por sua vez, pressionam $^{16}$ a estrutura psicofisiológica do indivíduo à "satisfação de certas necessidades originais"17. Há que se chegar, a partir de tais afirmações, em uma permanente e tensional relação entre as estruturas de um Mundo interno e as estruturas de um Mundo externo (o das vicissitudes da realidade objetiva) e é nesse entrecruzamento que as moções pulsionais

\footnotetext{
${ }^{13}$ FREUD, El yo y el ello, p. 40.

${ }^{14}$ Cf. FREUD. Moisés e o Monoteísmo: três ensaios, pp. 137-139.

${ }^{15}$ Cf. FREUD, Sobre la dinâmica de la trasferencia, p. 97.

${ }^{16}$ Lembrando-se que a pulsão é um conceito fronteiriço entre o anímico e o somático, um fator motor, uma soma de força ou uma medida da exigência de trabalho que ela representa: toda pulsão é uma parcela de atividade que exige o trabalho de satisfação (Cf. FREUD, Pulsiones y destinos de pulsión, pp. 105-134).

${ }^{17}$ FREUD, De guerra y muerte. Temas de actualidad, p. 283.
} 
manifestam-se na dimensão de moções pulsionais qualitativas. Escreve-nos Freud (no texto de 1915):

Em si, estas moções pulsionais não são nem boas e nem más. Nós as classificamos dessa forma, a elas e as suas exteriorizações, de acordo com a relação que mantém com as necessidades e as exigências da comunidade humana ${ }^{18}$.

O homem aculturado ou civilizado surge, nesse contexto, diante de moções pulsionais que são qualificadas como más, manifestando-se, por consequência, na dimensão de impulsos proibidos pela comunidade - como, por exemplo, as duas moções mais primitivas: o egoísmo e a crueldade. Diante disso, é preciso pensar o trabalho do coletivo ou da cultura sobre o individual na medida em que já existe ali todo um caminho (uma biografia sob a tensão interno-externo) de domesticação, de desvio ou deslocamento, bem como de sublimação ou inibição, de reinvestimento ou moralização de tais pulsões. Todavia, ressalta-nos Freud, essas formações reativas do homem aculturado (na qualidade de uma mudança de conteúdo) dão a aparência ou a ilusão de uma conversão: do egoísmo ao altruísmo, da crueldade à compaixão. Toda ambivalência de sentimentos e de impulsos afetivos tende a ser educada, docilizada e dissolvida em uma psique de massa. É por intermédio dessa aparência que "o caráter de uma pessoa [...] é classificado de 'bom' ou 'mal' [, mas] de maneira muito precária"19.

Lembremo-nos de que é no contexto da Primeira Grande Guerra Mundial que Consideraçôes atuais sobre a Guerra e a morte traz o tema da desilusão e leva Freud a refletir sobre aquela fúria enceguecida que aniquilou todos os laços comunitários entre os povos, cessando a repressão dos apetites maus e desmoronado com todos os graus de civilização e patrimônio cultural adquiridos: a crueldade, as deslealdades, as traições e as brutalidades tornaram-se manifestas. Uma questão fundamental aqui se coloca: De que modo, no indivíduo educado ou aculturado, o mal reaparece de forma tão vigorosa? Observemos que Freud nos lança nesse paradoxo, mas destaquemos, segundo suas palavras, que se trata de um mal que volta a aflorar com violência, isto é, ele não trata de um mal que aparece, mas que reaparece ${ }^{20}$. Há um impulso ou uma força psíquica que precisa ser investigada psicanaliticamente para que ela desvele, à luz desse reaparecer, a essência mais profunda de um mal anterior que se exterioriza no campo da História, da Coletividade, das Psiques de Massa. A morte e a destruição, em suma, são inseridas no devir da vida factual.

\footnotetext{
${ }^{18}$ Idem, p. 283.

${ }^{19}$ Idem, p. 283

${ }^{20}$ No original, lemos: "das bei dem so Erzogenen das Böse wieder so tatkräftig zum Vorschein Kommt." (FREUD, Zeitgemässes über Krieg und Tod, p. 331).
} 
Mesmo assim, não há no ser humano alguém que seja "bom" ou "mal" por inteiro, justamente porque a transformação das pulsões (qualificadas de) más é resultado de dois fatores que, segundo Freud, atuam no mesmo sentido: um fator interno e outro externo. Criação, destruição, devir e moral - por inibições externas que as pulsões experimentaram - estruturam aquilo o que se chamaria de caráter ${ }^{21}$. Por exemplo, em Três ensaios sobre a teoria da sexualidade (1905), vemos o esforço do autor em procurar conhecer tudo aquilo o que se poderia falar da vida e da função sexual humana - a partir de dados da biologia, mas - à luz da investigação psicológica disposicional e acidental, de modo que esses fatores constituir-se-ão como o campo de trabalho de sua indagação.

O que me interessa ressaltar nessa obra, em primeiro lugar, está no fato de que a pulsão sexual e a orientação de sua libido, que remetem tanto a uma fonte de estímulos intrassomática em contínuo fluir (fontes somáticas, zonas erógenas, prazer do órgão) quanto a relação exteriorizada pulsão-meta, apresentar-se-ão sob os pontos de vista a respeito da significatividade etiológica do inato e do acidentalmente vivenciado. Nas palavras de Freud, "é preciso juntar a repressão sexual, como fator interno, àqueles externos como restrição da liberdade, inacessibilidade do objeto sexual normal, perigos do ato sexual normal, etc"22. Logo, o caráter é o vivenciado do inato-acidental de forças anímicas (lembremo-nos da pulsão como um conceito fronteiriço) em que as exigências morais e estéticas (asco, sentimento de vergonha, nojo, educação, cultura, sublimação, formação reativa, defesas, repressão) estruturarão o desenvolvimento da organização sexual do indivíduo - constituindo sua biografia e a história de seus padecimentos.

Em segundo lugar - e na perspectiva da formação dessa biografia -, os traços de caráter do sujeito, sob o fundamento dos fenômenos psicossexuais, serão acessíveis ao estudo analítico acerca da produção de libido, de seu aumento-diminuição ou da distribuição-deslocamento, e isso na medida em que a "libido do eu" ou "libido narcísica" (pela representação psíquica de um quantum de libido) investe em objetos sexuais. Em outros termos, na medida em que os destinos da libido do eu se convertem em libido de objeto. Mas há uma investidura narcísica do eu que se conserva, sob essa biografia, em um estado originário desde a primeira infância ${ }^{23}$. Em $O$ objeto sexual do período do

\footnotetext{
${ }^{21} \mathrm{Em}$ A Interpretação dos Sonhos (vol. IV, item Os sonhos da morte de pessoas queridas), por exemplo, Freud nos mostrará que a criança é, por um lado, extremamente egoísta, sentindo com intensidade suas necessidades e esforçando-se sem rodeios para satisfazê-las (formação de um eu primário da criança egoísta); mas, por outro lado, ela se estrutura por moções altruístas e pela moral (formação de um eu secundário que se sobrepõe ao primário para inibi-lo). É por esse jogo de forças que o caráter do adulto se constitui. No Volume $\mathrm{V}$ da Interpretação dos Sonhos (item B. A regressão), Freud nos mostrará que "O que chamamos nosso caráter se baseia nos traços mnêmicos de nossas impressões; e, por certo, as que nos produziram um efeito mais forte, as de nossa primeira infância, são as que quase nunca se tornam conscientes." (FREUD, La interpretación de los sueños, p. 533).

${ }^{22}$ FREUD, Tres ensayos de teoria sexual, p. 155.

${ }^{23} \mathrm{Em}$ outros termos, desde o período de "latência sexual, do quinto ano completo às primeiras manifestações
} 
aleitamento (nos Três ensaios) vemos delinear-se, a partir da experiência do estado de desamparo do bebê e da vivência de satisfação pelo auxílio externo (na díade fomesaciação), aquilo o que Freud chamou de modelo paradigmático para todo vínculo de amor: a sexualidade perversa polimórfica da criança emerge de suas relações sociais com sua mãe $e^{24}$.

Trata-se, por consequência, de pensarmos na relação da criança com o peito da mãe pelo ato de mamar como um deslocamento da satisfação sexual (vinculada à ingestão de alimento) para o objeto externo ou para o seio da mãe como um objeto fora do próprio corpo da criança. No caso, a atividade sexual se divorciou da nutrição, mas ainda permanece uma parte considerável desse primeiro e mais importante dos vínculos sexuais (e paradigmático para a escolha do objeto): a finalidade de restaurar a felicidade perdida e de vencer o estado de desamparo. A criança aprende a amar as pessoas que a ajudaram a postergar o seu desamparo e a satisfizer as suas necessidades (segundo o modelo lactentelactante). Assim sendo, estrutura-se uma relação entre o amor sexual e os sentimentos de ternura e estima. Nas palavras de Freud,

Para a criança, o trato com a pessoa que dela cuida é uma fonte contínua de excitação sexual e satisfação das zonas erógenas, ainda mais porque essa que geralmente é a mãe - dedica-lhe sentimentos que se originam de sua própria vida sexual: acaricia, beija e embala a criança, claramente a toma como substituto de um objeto sexual de pleno direito ${ }^{25}$.

Infalivelmente, todos esses gestos de ternura exercerão também os seus efeitos sobre as pulsões sexuais e as zonas genitais do filho, bem como a sua intensidade, formando as bases inconscientes de sua biografia.

Com isso, o corpo erogenizado encontrar-se-á submetido à cultura e à linguagem, desvelando-se “imerso na cultura como superfície de inscrição da história” ${ }^{26}$. É sob essa situação antropológica fundamental do adulto-infans que o corpo erogenizado estará situado "no campo distintivo da situação humana [que] comporta já de saída uma historicidade fundamental" ${ }^{27}$. É por esta historicidade que a criança aprende a amar aos que remediaram o seu desamparo e é por ela que as constelações mais fundamentais do mecanismo psíquico invocam vergonha, asco e moralidade enquanto forças repressoras. $\mathrm{E}$ não é por acaso que, para Freud, a escrupulosidade da consciência moral será de grande

\footnotetext{
da puberdade (por volta dos onze anos)" - (FREUD, Carácter y erotismo anal, p. 154).

${ }^{24}$ Cf. FREUD, Tres ensayos de teoría sexual, p. 203 e OBEYESEKERE, The Work of Culture: Transformation in psychoanalysis and Anthropology, p. 73.

${ }^{25}$ FREUD, Tres ensayos de teoria sexual, p. 203.

${ }^{26}$ GARCIA-ROZA, Acaso e Repetição em Psicanálise, p. 62.

${ }^{27}$ HYPPOLITE, Ensaios de Psicanálise e Filosofia, p. 51.
} 
importância para a compreensão das formações defensivas e sintomáticas ${ }^{28}$. É desta maneira que percebemos "como certos pontos eletivos do próprio corpo podem não apenas servir de suporte para um prazer local, mas também lugar de encontro com o desejo" 29 .

No mesmo aspecto, Freud enfatizará a grande importância das pulsões para a vida psíquica do indivíduo, sobretudo - eis o que desejo aqui destacar - "para todas as realizações éticas e psíquicas" 30 . Todavia, que não se exclua desse movimento o campo da "inibição impositiva da sociedade"31. O caráter de um homem, conclui Freud nos Três ensaios, está construído com o material das excitações sexuais e das pulsões fixadas desde a infância e de outras adquiridas por sublimação, por repressão de moções perversas e por formações reativas e forças contrárias à satisfação direta, tais como vergonha, nojo e moral (que se opõem às pulsões sexuais como barreiras). Neste aspecto, escreverá Spielrein,

Freud remonta nossos impulsos amorosos posteriores, diretos ou sublimados, à idade infantil, na qual experimentamos as primeiras sensações de prazer por meio das pessoas que nos cuidaram. Nós sempre buscamos voltar a experimentar essas sensações de prazer, e quando o consciente já concebeu há muito um objetivo sexual normal, o inconsciente se ocupa de representações que eram carregadas de prazer em nossa primeira infância ${ }^{32}$.

Em Caráter e erotismo anal (1908), vemos que, segundo Freud, o caráter "se constrói a partir das pulsões constitutivas: os traços de caráter que permanecem são continuações inalteradas das pulsões originais, sublimações delas ou formações reativas a elas"33. E é dentro deste campo pulsional que destacamos agora duas grandes moções pulsionais contraditórias: amor e ódio. No texto As pulsões e seus destinos (1915) o leitor se depara com um importante paradoxo acerca das pulsões, ou melhor, acerca da íntima relação entre os sentimentos opostos amor-ódio e a vida sexual. Mas, desde os Três ensaios (1905), já nos deparávamos com a seguinte frase do autor: "A história da cultura humana ensina, para além de qualquer dúvida, que crueldade e pulsão sexual estão intimamente relacionadas"34. Diante de tais afirmações, coloquemos a seguinte questão: Como compreender a ligação do ódio com o desejo sexual (considerando o amar como a expressão de toda aspiração sexual)?

\footnotetext{
${ }^{28}$ Cf. FREUD, Manuscrito K. Las neuroses de defensa, pp. 260-269.

${ }^{29}$ LAPLANCHE e PONTALIS, Fantasia Originária, Fantasia das Origens, Origens da Fantasia, p. 83.

${ }^{30}$ FREUD, Tres ensayos de teoria sexual, p. 204.

${ }^{31}$ Idem, p. 209.

32 SPIELREIN, A destruição como origem do devir, p. 235.

${ }^{33}$ FREUD, Carácter y erotismo anal, p. 158.

${ }^{34}$ FREUD, Tres ensayos de teoria sexual, p. 144.
} 
É preciso partir do pressuposto de que o Eu se comporta de modo passivo diante do mundo externo (como um receptor de estímulos), mas também como um ativo ao reagir diante das estruturas do mundo: a realidade objetiva é agora ocupada com interesse. Do mesmo modo, reafirma-se aqui que "a percepção não é um processo puramente passivo, pois o eu envia de maneira periódica ao sistema percepção pequenos volumes de investimento" ${ }^{35}$. Nesse jogo de investimentos, o amar se coloca na esfera da relação de prazer do Eu com o objeto (no caso, do objeto sexual). No entanto, esse mesmo Eu odeia, abomina e persegue (com intenções destrutivas) os objetos que são fontes de sensações desprazerosas. Eis aí a tese de Freud: "os verdadeiros modelos de relação de ódio não advêm da vida sexual, mas da luta do Eu pela sua conservação e sua afirmação"36.

Amor (capacidade do Eu se satisfazer de modo autoerótico como parte de suas moções pulsionais) e Ódio (repúdio primordial do Eu narcísico perante o mundo externo portador de estímulos) possuem origens diversas e ganham diversidade sob a influência da relação prazer-desprazer - e isso na perspectiva (é o que me interessa aqui) de um existente na qualidade de in-divíduo (cindido, dividido entre consciente e inconsciente e entre forças psíquicas opostas). É nesse universo da luta entre pulsões (das pulsões sexuais e das pulsões do $\mathrm{Eu}$ ), da ambivalência amor-ódio e dos componentes de agressão que envolvem a pulsão sexual (sadismo-masoquismo) que o pensamento de Spielrein enriquece a discussão.

\section{Spielrein: entre estagnação, devir e destruição}

O que, a princípio, interessou à Sabina Spielrein - ao lidar com os problemas sexuais de suas pacientes - foi o fato de verificar a importância dessa poderosa pulsão e de perceber a pulsão sexual na qualidade de pulsão de procriação. Essa importância verificada se deve, justamente, pela observação da postura negativa dos neuróticos em relação ao ato sexual. As explicações, à época, lhe eram insuficientes na medida em que se buscava uma resposta a essa negatividade (ou seja, à repressão, ao recalque ou à sufocação enquanto formadores de sintoma) nos costumes, na educação e nas estruturas de uma cultura e de uma sociedade que visavam manter a pulsão sobre controle e que, por consequência, domesticavam (subjetivavam) as crianças a verem "a realização do desejo sexual como algo ruim, proibido"37. Logo, procurava-se as causas somente na exterioridade e focando-se apenas em um dos fatores constituintes das séries complementares. Seria preciso verificar se as representações carregadas de sentimentos que acompanhavam o comportamento sintomático encontravam-se enraizadas em complexos não meramente aleatórios ou

\footnotetext{
${ }^{35}$ FREUD, La Negación, p. 256.

${ }^{36}$ FREUD, Pulsiones y destinos de pulsión, p. 59.

${ }^{37}$ SPIELREIN, A destruição como origem do devir, p. 229.
} 
associados de forma arbitrária, mas em fatores que colocariam em dúvida a primazia da contingência histórica.

Spielrein destaca que, nesses casos patológicos, não é difícil perceber as frequentes representações de morte vinculadas aos desejos sexuais. Formava-se, por conseguinte, um paradoxo diante das demandas do inevitável desamparo pulsional e psíquico: de um lado, o desejo de viver (a autopreservação), de outro, o desejo de morrer (a destruição). Para a psicanalista russa, essa formação de conflito e sua consequente formação de sintoma têm como base

uma "imposição" de certas intenções, ou seja, de determinados complexos, os quais, como grupos de representações carregadas de afeto, obviamente demandam grande influência sobre as ações ${ }^{38}$.

Estes complexos, segundo a sua metapsicologia, transformam-se em grandezas psíquicas que anseiam por moldar a realidade, representando uma possibilidade de adquirir direito à existência e de tornar-se realidade: uma suposição se torna realidade, o complexo torna-se ser vivo autônomo. "Em pessoas que sofrem de Dementia-praecox, as quais transformam as representações do Eu em representações objetivas ou da espécie [, por exemplo,] cada uma das partes da personalidade é objetivada" 39 . Afinal, também para Spielrein, “a característica principal de um indivíduo é ser um 'divíduo', isto é, um ser dividido" ${ }^{40}$.

Dessa maneira, os complexos indicam a presença de um sujeito na qualidade de indivíduo, isto é, de duas vivências coexistentes: uma consciente e outra inconsciente - esta, especificamente, com a função da criação de tonalidades afetivas. O in-divíduo tem, na profundidade de seu $\mathrm{Eu}$, representações que pertencem a um passado que ultrapassa o âmbito do individual, como uma espécie de herança dos nossos ancestrais. Eis aí a visão filogenética de Spielrein dessas representações carregadas de pensamentos que, como ela mesma especifica, são "voltados para o prazer":

A nós parece que o sentimento de prazer faz parte do novo conteúdo de representação, pois nos alegramos com ele no presente, enquanto, porém, na realidade, nossa alegria pertence às vivências passadas e, nessa medida, nem mesmo apenas às nossas próprias vivências, uma vez que herdamos também a sedimentação das vivências de nossos ancestrais dentro de nós ${ }^{41}$.

\footnotetext{
${ }^{38}$ SPIELREIN, Sobre o conteúdo psicológico de um caso de esquizofrenia, p. 145.

${ }^{39}$ SPIELREIN, A Destruição como origem do devir, pp. 238-239.

${ }^{40}$ CAROPRESO, O instinto de morte segundo Sabina Spielrein, p. 416.

${ }^{41}$ SPIELREIN, Sobre o conteúdo psicológico de um caso de esquizofrenia, p. 213. A concepção de que o modo de pensar do inconsciente corresponda ao pensamento consciente de nossos ancestrais - Spielrein fala de representações herdadas - pode ter como referência a filogênese que Freud nos apresenta na Traumdeutung. "no estudo das psiconeuroses: o sonhar é em seu todo uma regressão às condições mais
} 
Para Spielrein, a vida psíquica inconsciente, com seus afetos, suas cadeias de representações e seus sentimentos, dilui o presente no passado, de maneira que o que ela entende por esta temporalidade - influenciada pelo contexto freudiano da Interpretação dos Sonhos ${ }^{42}$ - dar-se-á por um inconsciente que "subtrai do futuro seu significado autônomo: o futuro pessoal se torna passado filogenético generalizado, e este último mantém para o indivíduo ao mesmo tempo o significado de futuro"43. Há algo no inconsciente que está fora do tempo, algo que é presente-passado-futuro enquanto um fora do tempo.

Deste modo, o Eu, o caráter ou o in-divíduo, poderão ser compreendidos à luz do mecanismo inconsciente e de formações pessoais no presente (por estruturas, conflitos e representações) enquanto um esforço de diferenciação, mas também como uma sombra. Isto se dá sob o fundo de um passado filogenético de estruturas, conflitos e representações universais enquanto força de dissolução ou assimilação do diferenciado pelo qual se originam as vivências pessoais (singulares). É por esse dinamismo ativo em jogo (Psique do Eu $\leftarrow$ Psique da Espécie) e pela procura de uma causa movens do Eu consciente e inconsciente que a destruição poderia se colocar como a origem do devir. Com isso, formase um paradoxo com o qual Spielrein precisa se debruçar: a busca do autoprejuízo (prazer pela dor ou reação prazer do Eu na dor) e a pulsão de autoconservação.

Diante de tal problemática, cabe ressaltar que Spielrein observa que o componente da destruição na neurose se expressa nos sintomas de resistência sob duas formas: 1) uma tendência a ser absorvido como fantasia da destruição e do devir e 2) a negação (paralização) da vida com a morte (repulsa) da sexualidade - ambas estruturadas em sintoma. O que está colocado em jogo aqui é o processo do devir, ou melhor, a viabilidade de se pensar na destruição como causa do devir ${ }^{44}$ ou do desejo de destruição como um desejo mais intenso de devir ${ }^{45}$. A autora, para dar corpo à sua hipótese, nos traz dois interessantes exemplos"6: 1) a figura da árvore do conhecimento em seu duplo papel: símbolo da morte (ressurgindo na madeira da cruz de Cristo) e símbolo da gênese (criação) e 2) o sacrifício composto por duas funções: apropriação do elemento devir (reconduzir-se à mãe para renascer) e o abandono à destruição (morte sacrificial).

remotas do sonhador, uma revivificação de sua infância, das moções de impulso [Tiebregungen] dominantes nela e dos modos de expressão nela disponíveis. Por trás dessa infância individual nos é prometido um acesso à infância filogenética, ao desenvolvimento do gênero humano, do qual o indivíduo é de fato uma repetição abreviada, influenciada pelas circunstâncias da vida." (FREUD, La interpretación de los sueños, p. 542).

42 "Segundo Freud, [escreve Spielrein,] o inconsciente á atemporal na medida em que consiste apenas de desejos, os quais ele representa como realizados para o presente. Freud: A Interpretação dos Sonhos.” (SPIELREIN, A destruição como origem do devir, p. 234).

${ }^{43}$ SPIELREIN, Sobre o conteúdo psicológico de um caso de esquizofrenia, p. 216.

${ }^{44}$ Cf. SPIELREIN. De la transformation, p. 321.

${ }^{45}$ Cf. SPIELREIN, A destruição como origem do devir, p. 259.

${ }^{46}$ Cf. SPIELREIN, De la transformation, pp. 320-321. 
Para Spielrein, há uma bipolaridade nos impulsos de desejo nesse jogo de investimento da libido nos conteúdos representacionais e nas transformações de símbolos e das coisas em símbolos. Nas formações sintomáticas, por exemplo, pode-se observar que o lado do impulso positivo é concomitante à presença de um impulso negativo. A expressão de uma ideia pelo seu negativo ou pela inversão se repete na construção simbólica e foi isso que Spielrein pôde observar em sua prática clínica. Conclui-se daí que “A tendência à dissolução e assimilação possuiria componentes positivos (criativos) e negativos (destrutivos)" ${ }^{47}$. Todavia, ainda cabe perguntar se a vida psíquica consiste na vida do $\mathrm{Eu}$ e se possuímos impulsos poderosos que colocam em movimento conteúdos psíquicos sem considerar o bem estar ou o sofrimento do $\mathrm{Eu}^{48}$ ou a "miséria do ego" ${ }^{49}$.

É nesse próprio dinamismo, formador de conflito, que dois fluxos antagônicos da psique conduzem Spielrein a investigar a possibilidade da existência de um princípio do mecanismo anímico que poderia colocá-lo em movimento para além do princípio de prazer. Por um lado, ela compreende "que a principal característica do indivíduo consiste no fato de ele ser um indivíduo"50 - no caso, a psique do Eu se defende de toda forma de diluição de si à luz de uma (nas palavras de Spielrein) "ambição de se autoconservar na forma presente (capacidade de perseveração)" 51 . Esse "desejo de perseverar" - uma inércia da personalidade do $\mathrm{Eu}^{52}$ - é chamado por Spielrein de

pulsão de autoconservação [que] em nós corresponde à tendência de diferenciação e à capacidade de perseveração de uma partícula do Eu cristalizada externamente ou de toda personalidade do $\mathrm{Eu}^{53}$.

Trata-se, em suma, de uma pulsão estática que tem como finalidade proteger o Eu contra as influências externas que colocam em risco sua aparente totalidade e estabilidade.

Por outro lado, escreve Spielrein, há uma psique da espécie (pulsão de conservação da espécie, pulsão de procriação) que quer transformar essa representação cristalizada do Eu em uma representação impessoal, ou melhor, quer assimilar ou diluir essas representações diferenciadas do $\mathrm{Eu}$ e seus complexos individuais por aquelas que influenciaram a formação de culturas (as representações tipicamente impessoais e imemoriais da espécie). É diante de tal antagonismo que Spielrein lança a questão que mais nos interessa nessas reflexões. Ainda que ela concorde com Freud ao supor um mecanismo

\footnotetext{
${ }^{47}$ CAROPRESO, As hipóteses teóricas de Sabina Spielrein nas suas cartas a Carl Gustav Jung (1917-1918), p. 2.

${ }^{48}$ Cf. PIELREIN, A destruição como origem do devir, p. 236.

${ }^{49}$ CAROPRESO, O funcionamento mental e as bases ancestrais do psiquismo segundo Sabina Spielrein, p. 139.

${ }^{50}$ SPIELREIN, $A$ destruição como origem do devir, p. 237.

${ }^{51}$ Idem, p. 242.

${ }^{52}$ Cf. CAROPRESO, O instinto de morte segundo Sabina Spielrein, p. 417.

${ }^{53}$ SPIELREIN, A destruição como origem do devir, p. 260.
} 
psíquico que anseie pela obtenção de prazer e pela supressão do desprazer - um prazer, inclusive, que remonta regressivamente a fontes infantis -, ela nos lança a seguinte questão:

Resta, contudo, a questão se toda nossa vida psíquica consiste na vida do Eu. Afinal, não existem forças pulsionais em nós que colocam nosso conteúdo psíquico em movimento sem se preocuparem com o bem estar e o sofrimento do Eu? Será que as pulsões básicas conhecidas, a pulsão de autoconservação e de conservação da espécie, também significam para toda a vida psíquica aquilo que significam para a vida do $\mathrm{Eu}$, ou seja, a fonte do prazer e do desprazer? ${ }^{54}$.

Há, defende Sabina Spielrein, uma psique do Eu (inconsciente, inclusive) guiada por moções mais profundas que não se ocupam com as reações emocionais e com as reações afirmativas do Eu: o desejo do autoprejuízo e o regozijo pela dor vão além da vida do Eu (que só procura prazer). E como pensar essa busca prazerosa do autoprejuízo, do regozijo pela dor? Forma-se, à vista disso, um antagonismo: "a psique da espécie quer assimilar em si a psique do Eu recente, enquanto o Eu, sim, cada partícula do Eu possui a ambição de se autoconservar na forma presente (capacidade de perseveração)" 55 . Segue daí a inspiração nietzschiana de Spielrein: "O próprio ato de procriação consiste na autodestruição"56. Em outras palavras, para que surja o Übermensch é necessário que algo seja superado (destruído) no homem ${ }^{57}$. Por consequência (eis aí a tese da autora), a destruição leva ao devir. A morte da personalidade, o desejo de destruição corresponde a um desejo mais intenso: o devir. A condição humana é paradoxal e é ela que nos permite admirar essa espécie de paixão inútil da sua condição, afinal, "o que eu posso amar no homem é ser ele uma transição e um declínio" 58.

\section{Construção e devir. a condição humana entre indivíduo e cultura}

O fenômeno humano, à luz da metapsicologia de Spielrein, se constitui por uma tendência à diferenciação e por uma tendência à assimilação ou à dissolução. Em $A$ destruição como origem do devir, vemos que

\footnotetext{
${ }^{54}$ Idem, p. 236.

${ }^{55}$ Idem, p. 241.

${ }^{56}$ Idem, p. 254.

${ }^{57}$ Idem, p. 254.

${ }^{58}$ NIETZSCH, Assim falava Zaratustra, p. 360.
} 
A dissolução e assimilação de uma vivência pessoal na forma de uma obra de arte, de um sonho ou de uma simbólica patológica, a transforma em uma vivência da espécie e converte o "eu" em "nós". O surgimento do prazer ou desprazer está associado à criação ou ao desaparecimento da relação do $\mathrm{Eu}^{59}$.

Não há alteração, não há construção e nem dinâmica do devir (alteração pela ressurreição do indivíduo em uma nova forma) sem acontecer o aniquilamento do estado antigo. Para Spielrein, a morte (redentora) está a serviço do instinto sexual, ela é seu componente destruidor, mas que leva ao devir e à transformação (sentidos como morte): a pulsão de procriação é formada psicologicamente por dois componentes antagônicos (autoconservação e conservação da espécie) e é, portanto, uma pulsão de devir e de destruição $o^{60}$.

Se, para Nietzsche, a psicologia precisa ser novamente reconhecida como a rainha das ciências, como aquela que percorre o caminho para pensar os problemas fundamentais do fenômeno humano e como aquela que toma (nas palavras de Nietzsche, em Além do bem e do mal) "os afetos de ódio, inveja, cupidez, ânsia de domínio, como afetos que condicionam a vida, como algo que tem de estar presente, por princípio e de modo essencial, na economia global da vida"61, Freud e Spielrein, pode-se dizer, ajudam-nos a refletir sobre os dramas e as consequências (inevitáveis) do desamparo pulsional e psíquico dessa condição humana.

Se para Freud "A meta de toda a vida é a morte", pois "O inanimado esteve aí antes que o vivo" e "todo vivo morre, regressa ao inorgânico" ou ao "repouso do mundo inorgânico" (nas palavras do autor em Além do princípio do prazer) ${ }^{62}$, a pulsão de morte pode ser ali pensada como um movimento regressivo que produz morte e não o devir (enquanto criação, diferenciação). Ao passo que, para Spielrein, o instinto de morte não coloca como meta a destruição da estrutura psicofisiológica do existente, não visa à quietude do inorgânico, mas a destruição (devir) do Eu. Todavia, seja qual for a escolha que se fizer, Freud ou Spielrein, o contexto desse debate pode nos oferecer trajetórias para pensarmos em uma das fundamentais estruturas da condição humana: a dialética ErosThanatos.

\footnotetext{
${ }^{59}$ SPIELREIN, A destruição como origem do devir, p. 260.

${ }^{60}$ Explica-nos Renata Cromberg: "ela não apenas junta morte e sexualidade, como coloca a repugnância e a angústia ligadas à própria sexualidade, à própria pulsão, a algo intrínseco a ela. O inimigo é interno, é a própria pulsão sexual que traz em si a fonte da angústia; a febre amorosa, a paixão, naquilo que o instante supremo do gozo sexual traz de contato com a evanescência, com a finitude, da qual o eu quer se proteger, se esconder e não consegue, angustiando-se quando está diante da potência da sexualidade [transformação corporal, descarga sexual, saída de si mesmo]." (CROMBERG, Sabina Spielrein: uma pioneira da psicanálise, p. 292).

${ }^{61}$ NIETZSCHE, Além do bem e do mal, p. 28.

${ }^{62}$ FREUD, Más allá del principio de placer, pp. 38 e 60.
} 
A Psicanálise abre caminhos para refletir sobre o quanto as díades determinaçãocasualidade, Eu-Nós, Ontogênese-Filogênese, destruição-devir podem levar o pesquisador a verificar a sua importância histórica para o diálogo com as humanidades e isso na medida em que é possível constatar que a genealogia do aparelho anímico sustenta (afetase e afeta) a relação inevitável de mutualidade entre as psiques de massa e a psique individual. Um sistema simbólico, no caso, é pessoal e cultural, de modo que a realidade seja psiquicamente e culturalmente construída, psiquicamente real para o indivíduo e para o grupo do qual participa. Eis o paradoxo freudiano: as forças mecânicas dos instintos dãose em relação com as complexidades da condição humana ${ }^{63}$. Não poderia ser diferente, pois "a essência da natureza humana não é somente a de ser condicionada, mas também de ser ela mesma condicionante" 64 . A Psicanálise tomou por objeto a psique individual, mas não deixou de explorar as bases afetivas do vínculo indivíduo-sociedade.

A história de uma civilização, portanto, relata os caminhos percorridos pela ligação (Bindung) entre desejos insatisfeitos e frustrados (Versagung) e a realidade - um caminho de aventuras iluminado pelas vicissitudes das pulsões. "A cultura não é um resíduo inútil da pulsão, mas a multiplicação de suas possibilidades de satisfação" ${ }^{65}$. Entre denegação e ressarcimento pela deficiente satisfação dos desejos, mito, religião e moralidade se inserem na estrutura cultural enquanto mediadores da adaptação ao mundo exterior, ao mesmo tempo em que possibilitam uma forma de ressarcimento ${ }^{66}$. Esta, por sua vez, alicerça-se em um conjunto de moções pulsionais em que o indivíduo e o grupo são afetados por um movimento dialético entre criação, identificação e destruição, entre amor e aniquilamento. Quando se pensa na clínica, sobretudo, o devir interpõe-se como condição inevitável, dado que uma personalidade é produzida sob o efeito de uma espécie de elasticidade orgânica em que ela se vê lançada para além dos limites de seu Eu-Pele (daí a ideia de transbordamento), isto é, para além dos limites da existência orgânica e do sistema de proteção de sua individualidade.

Falar de pulsão sexual, de trocas de substâncias e de tudo o que a sexualidade impulsiona em suas catexias - no sentido ampliado de sexualidade que propõe Freud nos Três Ensaios (1905) -, leva-nos a refletir sobre as transformações corporais, as descargas pulsionais e as cargas de afeto por elas mobilizadas que não deixam intacto o aparelho anímico. Os conteúdos de vivência enraízam-se numa trama de existência entre as representações conscientes - portanto, na temporalidade presente e no sentido de uma diferenciação - e as profundezas do inconsciente - fora do tempo e no sentido da indiferenciação -, trazendo por consequência a inscrição de traços no psiquismo. Compreendamos esses traços no sentido que Spielrein e Freud poderiam nos proporcionar:

\footnotetext{
${ }^{63}$ Cf. OBEYESEKERE, The Work of Culture: Transformation in psychoanalysis and Anthropology, p. 245.

${ }^{64}$ RÓHEIM, Psychanalyse et anthropologie, p. 486.

${ }^{65}$ GARCIA-ROZA, Acaso e Repetição em Psicanálise, p. 17.

${ }^{66}$ Cf. FREUD, El interés por el psicoanálisis, pp. 188-189.
} 
Não existe, do ponto de vista psíquico, percepção pura do presente sem ligação com a memória inconsciente do passado. Foi isso o que Freud resumiu sobre a concepção da temporalidade na teoria psicanalítica na parte I de Mal estar na Cultura ${ }^{67}$.

Essa espécie de tensão temporal (diferenciação-indiferenciação) inscreve-se numa totalidade corporal, numa armadura de feixes sensórios e tentáculos que asseguram as condições para incorporar uma imagem do mundo e nela interferir ${ }^{68}$. Mas essa incorporação se dá sob a condição universal humana da intersensorialidade: das experiências corporais de desamparo ao seio da mãe. Nessa relação de entendimento ou comunicação (Verständigung) e de motivos morais (moralischen Motive) ${ }^{69}$ a destrutividade, as tendências antissociais e anticulturais afetam a conduta do indivíduo em sociedade, de forma que essas tendências sejam, enquanto fatos psicológicos, de valor decisivo para a formação da cultura ${ }^{70}$ - lembremo-nos do empobrecimento e da perda de nitidez que causaria a oposição de uma psicologia individual de uma psicologia da massa. Os caminhos e os investimentos pulsionais na procura de satisfação não desconsideram as relações do indivíduo com o outro: o Mundo pode se tornar auxílio ou adversário nessa aventura do drama humano.

Ora, Freud encerra O futuro de uma ilusão (1927) para nos mostrar que o próprio aparelho psíquico é um elemento do mundo externo e este, por sua vez, aparece em consequência da particularidade de nossa organização. É preciso, portanto, levar em consideração o nosso aparelho psíquico perceptível, de modo que as nossas investigações não se tornem uma abstração vazia e sem interesse prático. É na dependência prolongada do outro (o/a auxiliador/a externo) que o bebê é inserido na tensão temporal, na temporalidade histórica e em suas formas de organização moral e social, de modo que os vestígios da pré-história esquecida retornam do esquecimento e se impõem com poder e fortes influências sobre essa relação.

No caso, encontram-se ativos na vida psíquica do indivíduo tanto conteúdos vivenciados em sua singularidade (Eu/Diferenciação) quanto conteúdos inatos de origem filogenética (Nós/Indiferenciação). Há, assim sendo, uma sustentação para o psiquismo que é dupla, isto é, uma sobre o corpo biológico e outra sobre o corpo social. É deste modo que a vida orgânica e a vida social "têm ambas tanta necessidade de um apoio quase constante sobre o psiquismo individual [...] como este último tem necessidade de um apoio recíproco sobre um corpo vivo e sobre um grupo social vivo"71.

\footnotetext{
${ }^{67}$ CROMBERG, Sabina Spielrein: uma pioneira da psicanálise, p. 296.

${ }^{68}$ Cf. FREUD, Sobre a Concepção das Afasias: um estudo crítico, p. 68.

${ }^{69}$ Cf. FREUD, Proyecto de psicologia, pp. 362-363.

${ }^{70}$ Cf. FREUD, El porvir de una ilusión, p. 7.

${ }^{71}$ ANZIEU, $O$ Eu-Pele, p. 4.
} 
Com isso, creio que Freud e Spielrein poderiam ser lidos segundo uma noção de destruição (desagregar, desinvestir) no campo da historicidade de uma personalidade em vida. A noção de construção estaria vinculada à possibilidade de fazer falar a imagem de um passado, de modo que o conservar e o resgatar confrontar-se-iam com a possibilidade de destruição, dissipação e dilaceramento. André Green, em Pulsão de Morte, Narcisismo Negativo, Função Desobjetalizante (1988), nos mostrará, por exemplo, que o objeto é revelador da pulsão e condição de seu devir, de modo que pulsão de vida e esforço de diferenciação possam remeter à função objetalizante ou de simbolização, criando relações com o objeto e transformando estruturas em objeto. Dessa forma, "a meta da pulsão de morte é realizar ao máximo uma função desobjetalizante através do desligamento"72. Logo, não só o objeto é atacado, mas também as ligações que funcionam como seus substitutos: desinvestir é destruir.

À vista disso, a comparação freudiana com o trabalho de arqueologia não se colocaria na relação com o paciente para desviá-lo do tempo e mantê-lo aprisionado a uma parcela de seu passado. O trabalho de uma escavação exige destruição para reconstruir através do que se oculta sob os escombros. $\mathrm{Na}$ análise, o desviar-se do tempo passado darse-ia como uma forma de impedir a sua destruição: o olhar para o passado para restituí-lo destina essa temporalidade à destruição. Trata-se, enfim, de um convite ao leitor para debruçar-se, a partir das hipóteses de Spielrein e do que ela estimula a resgatar de Freud, sobre "o problema de saber se uma repetição é possível e qual o significado que tem, de saber se uma coisa ganha ou perde em repetir-se"73 ou de pensar na noção de temporalidade na perspectiva de que “A ‘construção' pressupõe a 'destruição”"74. Eu e Nós, Indivíduo e Cultura, Acaso e Herança Arcaica já nos provoca tal discussão.

\section{Observações finais}

O movimento do percurso freudiano pode ser apresentado como "um percurso histórico de significante a significado, de exegese - e este aprofundamento do desejo humano que, em sua ambivalência, é tanto Eros como Morte"75. Afinal, Eros e Thanatos, Regressão e Progressão, Eu e herança arcaica, remetem ao modo pelo qual um fragmento do passado toca e tocaria a atualidade. A relação de continuidade entre história anterior e história posterior encontrar-se-ia mergulhada em um campo de forças entre o herdado e as

\footnotetext{
72 GREEN, Pulsão de Morte, Narcisismo Negativo, Função Desobjetalizante, p. 60.

${ }^{73}$ KIEKERGAARD, A Repetição, p. 31.

74 BENJAMIN, Passagens, p. 512. Sobre o conceito de construção no pensamento de Benjamim e Freud, conferir CHAVES, Construções na história, construções em análise: presença de Freud na filosofia da história de Walter Benjamin, pp. 33-44.

${ }^{75}$ HYPPOLITE, Ensaios de Psicanálise e Filosofia, p. 38.
} 
vivências casuais: o presente poderia reencontrar o seu valor para além da repetição. Essa história individual, coletiva, consciente e inconsciente também se constrói frente às exigências das grandes necessidades vitais que a linha demarcatória (real e imaginária) do Eu-Pele apresenta como instrumento de lugar de troca com o outro, de interação com o entorno e com os fatos sociais em uma constante negociação com a satisfação das pulsões $^{76}$. Talvez seja no campo da biologia, dos destinos da espécie humana, da história de formação da cultura e das (o)posições Mundo interno-Mundo externo que podemos compreender a frase enigmática de Freud a nos afirmar a relação entre o Id hereditário e seus resíduos de inumeráveis existências-eu ou mesmo a clássica afirmação na $31^{a}$ Conferência (1933 [1932]): Onde era Id, há de ser Eu (Wo Es war, soll Ich werden).

Entre "onde era" e "há de ser" há todo um movimento de trabalho da cultura [Kulturarbeit] sobre o não-pessoal ou indiferenciado, sobre o não espacializado e o não temporalizado, mobilizando intensidades indomadas no nível de uma "determinação indeterminada" 77 . A imensa diversidade da vida, submetida às condições da ancestralidade e aos acontecimentos acidentais de uma singularidade ou de um grupo, é mobilizada por volumes de força colocadas à disposição para esse trabalho cultural: as magnitudes constitucionais e as influências da vida, a pressão [Drang] das pulsões e as imposições da cultura e dos ideais educativos (lembremo-nos de que em si, as pulsões não são nem boas e nem más). É nesse conjunto de reflexões que poderíamos pensar no protagonismo da morte ou do pulsional da morte como o que "está para além da representação e do inconsciente, [que] remete ao que é antes de ser [...]: há sujeito quando lhe falta ser"78. Mais uma vez, o que se pode ganhar ou perder com a noção de repetição nesse contexto?

Tanto em Freud quanto em Spielrein podemos vislumbrar que o perigo não é só o social, o inimigo encontra-se também em si mesmo, isto é, nas estruturas dinâmicas do próprio Eu. Seja pelo jogo de forças do Id-Eu-Superego de Freud ou pelo jogo de forças entre a Psique do Eu e a Psique da Espécie de Spielrein, a dinâmica que essas forças produzem colocam a vida em um estado tensional permanente entre a necessidade de diferenciação (realização de desejo de uma personalidade na factualidade de sua vida) e a assimilação ou diluição (representações da herança arcaica ou representações típicas). É neste ponto de encontro do “onde era-há de ser” os sistemas simbólicos culturais são espacializados e temporalizados sob aquilo que emerge do indiferenciado em um processo de socialização e enraizamento em uma cultura: "de facto, pode-se reformular razoavelmente a famosa afirmação de Freud 'onde o Id estava, haverá ego' em 'onde o ego está, haverá Id'”79.

\footnotetext{
${ }^{76}$ Cf. ANZIEU, O Eu-Pele, p. 03.

77 GREEN, El trabajo de lo negativo, p. 250.

${ }^{78}$ BAIRRÃO, O Protagonismo da Morte, p. 78.

${ }^{79}$ OBEYESEKERE, The Work of Culture: Transformation in psychoanalysis and Anthropology, p. 252.
} 
Seja qual for o ponto de partida, a negociação entre o impulso à liberdade e a vontade da massa - como encontra o leitor em O Mal-estar na Cultura - mobiliza a tensão entre a destruição (dos valores, dos hábitos ou dos discursos) e o devir à luz de uma permanente negociação instável entre o Nós e o Eu. Daí a importância de uma reflexão sobre o caráter disposicional e adquirido da condição humana, convidando-nos a constatar a existência

de um aparelho psíquico flexível, plástico, cujas determinações (biológica, da experiência, cultural) conflitantes resultam menos numa visão determinista do ser humano que numa visão do ser humano como a expressão de forças que taticamente se compõem, mas que são inconciliáveis [forças, tendências que se juntam, se chocam, avançam e recuam $]^{80}$.

Afinal, é importante ter como pano de fundo certo grau de imprevisibilidade que envolve a discussão, pois não se pode prever os que serão suprimidos pela dialética criação-destruição e nem qual a forma mais enriquecida do Eu a ressurgir dela. Falar em devir implica em articular a dimensão de um não-saber (não-previsibilidade) sobre quais fatores se revelarão (ainda que se considere as condições de uma herança arcaica) mais fortes ou mais fracos no indivíduo em seu afrontamento com as exigências e os imperativos da cultura.

Em outros termos, "as causas são sempre de reconhecimento seguro na direção da

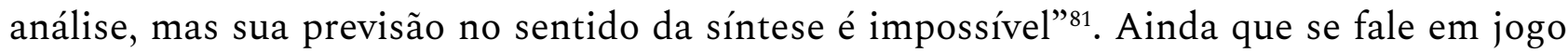
de forças ou de uma economia de princípios, estas dar-se-ão sempre dentro de um campo da linguagem e de um sistema de símbolos pessoais e culturais e, para que uma nova forma do Eu e da Cultura (na luta indivíduo-massa) volte a aparecer, é preciso diluição, destruição, morte. Considera-se, por consequência, uma elasticidade orgânica [organischen Elastizität] entre uma força conservadora e aquela da reprodução de um estado anterior ${ }^{82}$ pelo qual vislumbra-se a alteração e ressurreição do indivíduo e da massa em novas configurações. E não seria deste modo que "as realizações psíquicas mais significativas e também mais dolorosas da época da puberdade, o desprendimento da autoridade dos pais, através do qual se cria a oposição [...] da nova geração em face da antiga" ${ }^{33}$ possibilitariam falar de avanço (modificação) cultural entre gerações?

\footnotetext{
${ }^{80}$ CORRÊA, Filogênese na Metapsicologia Freudiana, pp. 367-368.

${ }^{81}$ FREUD, Sobre la psicogénesis de un caso de homosexualidad feminina, p. 160.

${ }^{82}$ Cf. FREUD. Más allá del principio de placer, p. 36 e FREUD, Dos artículos de enciclopédia: "Psicoanálisis"

y “Teoría de la libido”, p. 254.

${ }^{83}$ FREUD, Tres ensayos de teoria sexual, p. 207.
} 
Fica, com isso, a possibilidade de compreender o trabalho da cultura (Kulturarbeit ${ }^{84}$, segundo o contexto freudiano e à luz do universo spielreiniano, a partir da ideia de que

a psique da espécie [o Id hereditário e seus resíduos de inumeráveis existências-eu] quer assimilar em si a psique do Eu recente enquanto [...] cada partícula do Eu possui ambição de se autoconservar na forma presente [...]. Mas a psique da espécie [...] nega o Eu atual, consegue fazê-lo de novo por meio da negação, pois a partícula do Eu submersa volta a emergir travestida de novas representações, mais rica do que nunca ${ }^{85}$.

Para encerrar, se faz pertinente a leitura de um trecho de Nietzsche, em Além do bem e do mal(1886):

Os fisiólogos deveriam refletir, antes de estabelecer o impulso de autoconservação como o impulso cardinal de um ser orgânico. Uma criatura viva quer antes de tudo dar vazão a sua força - a própria vida é vontade de poder -: a autoconservação é apenas uma das indiretas, mais frequentes consequências disso. - Em suma: nisso, como em tudo, cuidado com os princípios teleológicos supérfluos! - um dos quais é o impulso de autoconservação [...]. Assim pode o método, que deve ser essencialmente economia de princípios ${ }^{86}$.

Enfim, como nos provoca Nietzsche, não se escapará do caminho aberto para versões e refinamentos da hipótese da alma, como mortal, como pluralidade do sujeito ou como estrutura social dos impulsos e dos afetos, em suma, não nos esquivaremos do estar condenados à invenção, à destruição ou à descoberta.

\section{Referências}

ANZIEU, Didier. O Eu-Pele. Tradutoras Zakie Yazigi Rizka-lah. São Paulo: Casa do Psicólogo, 1989.

\footnotetext{
${ }^{84} \mathrm{Um}$ trabalho cultural para fortalecimento do Eu, ampliação do seu âmbito de percepção e enriquecimento de sua organização para apropriar-se de novas parcelas do Id (daí a célebre afirmação "Onde era Id, há de ser Eu” - Cf. FREUD, 31ํㅡ Conferencia. La descomposición de la personalidad psíquica, pp. 53-74). Toda cultura, em suma, deve edificar-se sobre uma coerção ao trabalho e sobre uma renúncia ao pulsional, de modo que o trabalho da cultura (ou a história da cultura) mostrará os caminhos que o ser humano empreendeu para estabelecer a ligação (Bindung) de seus desejos sob as condições cambiantes de concessão [Gewährung] e frustração [Versagung] por parte da realidade.

${ }^{85}$ SPIELREIN, A destruição como origem do devir, pp. 241-242.

${ }^{86}$ NIETZSCHE, Além do bem e do mal, p. 19.
} 
BAIRRÃO, José F. Miguel H. Prefácio. In: CORRÊA, Fernanda Silveira. Filogênese na metapsicologia freudiana. Campinas: Editora da Unicamp, 2015.

BAIRRÃO, José F. Miguel H. O Protagonismo da Morte. In: MONZANI, Luiz Roberto; SORIA, Ana Carolina Soliva (Org.). Freud: Filosofia e Psicanálise. São Carlos: EdUFSCar, 2019.

BENJAMIN, Walter. Passagens. Tradução Irene Aron, Cleonice Paes Barreto Mourão. Belo Horizonte: Editora UFMG; São Paulo: Imprensa Oficial do Estado de São Paulo, 2009.

CAROPRESO, Fátima. O instinto de morte segundo Sabina Spielrein. Psicologia USP, São Paulo, v. 27, n. 3, p. 414-419, set./dez. 2016. Disponível em: < https://www.scielo.br/scielo.php?script=sci_arttext\&pid=S010365642016000300414\&lng=pt\& tlng=pt>. Acesso em: 02 junho 2020.

CAROPRESO, Fátima. As hipóteses teóricas de Sabina Spielrein nas suas cartas a Carl Gustav Jung (1917-1918). Psicologia USP, São Paulo, v. 30, p. 1-9, Dec. 2019. Disponível em: https://www.scielo.br/scielo.php?pid=S010365642019000100231\&script=sci_arttext t. Acesso em: 02 junho 2020.

CAROPRESO, Fátima. O funcionamento mental e as bases ancestrais do psiquismo segundo Sabina Spielrein. Tempo Psicanalítico, Rio de Janeiro, v. 49, no. 2, p. 126-151, Dec. 2017. Disponível em:

http://pepsic.bvsalud.org/scielo.php?script=sci_arttext\&pid=S010148382017000200007. Acesso em: 02 junho 2020.

CHAVES, Ernani. Construções na história, construções em análise: presença de Freud na filosofia da história de Walter Benjamin. In: SAFATLE, Vladimir; Manzi, Ronaldo (Org.). A filosofia após Freud. São Paulo: Humanitas, 2008, pp. 33-44.

CORRÊA, Fernanda Silveira. Filogênese na metapsicologia freudiana. Campinas: Editora da Unicamp, 2015.

CROMBERG, Renata Udler. SABINA SPIELREIN: uma pioneira da psicanálise. Tradução Renata Dias Mundt. São Paulo: Livros da Matriz, Vol. 1, 2014.

FREUD, S. Proyecto de psicología. In: Obras completas, v. I (1950 [1895]). Traducción de José Luis Etcheverry. Buenos Aires: Amorrortu editores, 1994.

FREUD, S. Manuscrito K. Las neuroses de defesa. In: Obras completas, v. I (1896). Traducción de José Luis Etcheverry. Buenos Aires: Amorrortu editores, 1994.

FREUD, S. La interpretación de los sueños. In: Obras completas, v. IV, V (1900-1901). Traducción de José Luis Etcheverry. Buenos Aires: Amorrortu editores, 1994.

FREUD, S. Caráter y erotismo anal. In: Obras completas, v. IX (1908). Traducción de José Luis Etcheverry. Buenos Aires: Amorrortu editores, 1993. 
FREUD, S. Tres ensayos de teoria sexual. In: Obras completas, v. XI (1905). Traducción de José Luis Etcheverry. Buenos Aires: Amorrortu editores, 1995.

FREUD, S. Un recuerdo infantil de Leonardo da Vinci. In: Obras completas, v. XI (1910). Traducción de José Luis Etcheverry. Buenos Aires: Amorrortu editores, 1994.

FREUD, S. Sobre la dinámica de la trasferencia. In: Obras completas, v. XII (1912). Traducción de José Luis Etcheverry. Buenos Aires: Amorrortu editores, 1995.

FREUD, S. Tótem y tabú. Algunas concordancias en la vida anímica de los salvajes y de los neuróticos. In: Obras completas, v. XIII (1913 [1912-1913]). Traducción de José Luis Etcheverry. Buenos Aires: Amorrortu editores, 1994.

FREUD, S. El interés por el psicoanálisis. In: Obras completas, v. XIII (1913). Traducción de José Luis Etcheverry. Buenos Aires: Amorrortu editores, 1994.

FREUD, S. Pulsiones y destinos de pulsión. In: Obras completas, v. XIV (1915). Traducción de José Luis Etcheverry. Buenos Aires: Amorrortu editores, 1995.

FREUD, S. De guerra y muerte. Temas de actualidad. In: Obras completas, v. XIV (1915). Traducción de José Luis Etcheverry. Buenos Aires: Amorrortu editores, 1995.

FREUD, S. 23를 conferencia. Algunas perspectivas sobre el desarrollo y la regresión. In: Obras completas, v. XVI (1917 [1916-1917]). Traducción de José Luis Etcheverry. Buenos Aires: Amorrortu editores, 1994.

FREUD, S. Una dificultad del psicoanálisis. In: Obras completas, v. XVII (1917 [1916]). Traducción de José Luis Etcheverry. Buenos Aires: Amorrortu editores, 1994.

FREUD, S. Nuevos caminos de la terapia psicoanalítica. In: Obras completas, v. XVII (1919 [1918]). Traducción de José Luis Etcheverry. Buenos Aires: Amorrortu editores, 1994.

FREUD, S. Moisés e o Monoteísmo: Três Ensaios. In: Obras Completas, v. 19 (1939 [19341938]). Tradução Paulo César de Souza. São Paulo: Companhia das Letras, 2018.

FREUD, S. Más allá del principio de placer. In: Obras completas, v. XVIII (1920). Traducción de José Luis Etcheverry. Buenos Aires: Amorrortu editores, 1995.

FREUD, S. Psicología de las masas y análisis del yo. In: Obras completas, v. XVIII (1921). Traducción de José Luis Etcheverry. Buenos Aires: Amorrortu editores, 1995.

FREUD, S. Sobre la psicogénesis de un caso de homosexualidad feminina. In: Obras completas, v. XVIII (1920). Traducción de José Luis Etcheverry. Buenos Aires: Amorrortu editores, 1995.

FREUD, S. Dos artículos de enciclopédia: “Psicoanálisis” y “Teoría de la libido”. In: Obras completas, v. XVIII (1923 [1922]). Traducción de José Luis Etcheverry. Buenos Aires: Amorrortu editores, 1995. 
FREUD, S. El yo y el ello. In: Obras completas, v. XIX (1923). Traducción de José Luis Etcheverry. Buenos Aires: Amorrortu editores, 1993.

FREUD, S. La Negación. In: Obras completas, v. XIX (1925). Traducción de José Luis Etcheverry. Buenos Aires: Amorrortu editores, 1993.

FREUD, S. El porvenir de una ilusión. In: Obras completas, v. XXI (1927). Traducción de José Luis Etcheverry. Buenos Aires: Amorrortu editores, 1994.

FREUD, S. Zeitgemässes über Krieg und Tod. In: FREUD, S. Gesammelte Werke, v. X (1915). London: Imago Publishing CO., LTD, 1946.

FREUD, S. 31ํㅡㄹ Conferencia. La descomposición de la personalidade psíquica. In: Obras completas, v. XXII (1932-1936). Traducción de José Luis Etcheverry. Buenos Aires: Amorrortu editores, 1993.

FREUD, S. Sobre a Concepção das Afasias: um estudo crítico. Tradução Emiliano de Brito Rossi. Belo Horizonte: Autêntica Editora, 2013.

GARCIA-ROZA, Luiz Alfredo. Acaso e Repetição em Psicanálise: uma introdução à teoria das pulsões. 2 ${ }^{\mathrm{a}}$ ed. Rio de Janeiro: Zahar, 2014.

GREEN, André. Pulsão de Morte, Narcisismo Negativo, Função Desobjetalizante. In: GREEN, André (et al.). A Pulsão de Morte. São Paulo: Editora Escuta, 1988, pp. 53-64.

GREEN, André. El trabajo de lo negativo. Traducción Irene Agoff. Buenos Aires: Amorrortu, 2006.

HYPPOLITE, Jean. Ensaios de Psicanálise e Filosofia. Tradução André Telles. Rio de Janeiro: Timbre/Taurus, 1989.

KIERKEGAARD, Soren. A Repetição. Tradução José Miranda Justo. Lisboa: Relógio D `Água, 2009.

LAPLANCHE, Jean e PONTALIS, J-B. Fantasia Originária, Fantasia das Origens, Origens da Fantasia. Tradução Álvaro Cabral. Rio de Janeiro: Zahar, 1993.

NIETZSCHE, Friedrich. Assim Falava Zaratustra. Tradução Mário Ferreira dos Santos. $3^{\mathbf{a}}$ ed. Petrópolis, RJ: Vozes, 2014.

NIETZSCHE, Friedrich. Além do bem e do mal: prelúdio a uma filosofia do futuro. Tradução Paulo César de Souza. São Paulo: Companhia das Letras, 2005.

RÓHEIN, Géza. Psychanalyse et anthropologie: Culture-Personnalité-Inconscient. Traduit par Marie Moscovico. Paris: Gallimard, 1950.

SPIELREIN, Sabina. A destruição como origem do devir. In: CROMBERG, Renata Udler. SABINA SPIELREIN: uma pioneira da psicanálise. Tradução Renata Dias Mundt. São Paulo: Livros da Matriz, Vol. 1, 2014, pp. 227-278. 
SPIELREIN, Sabina. Sobre o conteúdo psicológico de um caso de esquizofrenia. In: CROMBERG, Renata Udler. SABINA SPIELREIN: uma pioneira da psicanálise. Tradução Renata Dias Mundt. São Paulo: Livros da Matriz, Vol. 1, 2014.

SPIELREIN, Sabina. De la Transformation. In: Les premiers psychanalystes. Minutes de la Société psychanalytique de Vienne, 1910-1911, V. III. Paris: Gallimard, 1979, pp. 319-325.

OBEYESEKERE, Gananath. The Work of Culture: Transformation in psychoanalysis and Anthropology. Chicago: University of Chicago Press, 1996. 